11

\title{
Кристаллографические особенности структуры мартенсита сплава $\mathrm{Ni}_{47} \mathrm{Mn}_{42} \mathrm{In}_{11}$
}

\author{
() Ю.В. Калетина, И.Г. Кабанова, Н.Ю. Фролова, В.М. Гундырев, А.Ю. Калетин \\ Институт физики металлов им. М.Н. Михеева УрО РАН, \\ Екатеринбург, Россия \\ E-mail: kaletina@imp.uran.ru
}

(Поступила в Редакцию 4 апреля 2017 г.)

Исследована структура сплава $\mathrm{Ni}_{47} \mathrm{Mn}_{42} \mathrm{In}_{11}$ после отжига. Показано, что при охлаждении мартенситное превращение в сплаве $\mathrm{Ni}_{47} \mathrm{Mn}_{42} \mathrm{In}_{11}$ идет с образованием модулированного мартенсита 14M. Проведен кристаллографический анализ структуры мартенсита. Определены ориентационные соотношения между высокотемпературной аустенитной фазой и мартенситом, а также габитусные плоскости пластин мартенсита.

Работа выполнена в рамках государственного задания ФАНО России (тема „Структура“, № 01201463331) при частичной поддержке РФФИ (проект № 16-03-00043).

DOI: 10.21883/FTT.2017.10.44969.111

\section{1. Введение}

Трехкомпонентные сплавы Гейслера на основе $\mathrm{Ni}-\mathrm{Mn}-\mathrm{In}$ относятся к многофункциональным материалам, проявляющим эффект памяти формы, магнетокалорический эффект и другие свойства в области фазовых переходов. В нестехиометрических сплавах $\mathrm{Ni}-\mathrm{Mn}-\mathrm{In}$, как показали исследования [1-5], наблюдается сложная последовательность фазовых переходов. Сначала при понижении температуры происходит магнитный переход высокотемпературной фазы из пара- в ферромагнитное состояние. Затем реализуется мартенситное превращение с образованием антиферро- или парамагнитного мартенсита, который в области низких температур изменяет свое магнитное состояние, то есть в мартенситной фазе наблюдается магнитный переход. Температуры мартенситного перехода изменяются при отклонении от стехиометрии и легировании сплавов Гейслера $[3,4]$.

Изучение структуры фаз - исходной (высокотемпературной) и образующейся в ходе мартенситного превращения, а также их взаимосвязи - необходимо для понимания причин, вызывающих появление тех или иных значений аномальных магнитных и механических свойств в области фазовых переходов. Однако такие структурные исследования малочисленны. Изучение кристаллографических особенностей структуры представляет интерес с точки зрения получения информации о влиянии структурного и магнитного упорядочения на функциональные характеристики сплавов Гейслера $\mathrm{Ni}-\mathrm{Mn}-\mathrm{In}$.

Проведенные нами ранее исследования тонкой структуры сплавов $\mathrm{Ni}_{47-x} \mathrm{Mn}_{42+x} \operatorname{In}_{11}$ (где $x$ от 0 до 2) после отжига методами оптической металлографии, сканирующей и электронной микроскопии, а также рентгеноструктурным методом показали, что при замещении атомов никеля атомами марганца происходят закономерные изменения фазового состава, структуры и температуры мартенситного перехода. При охлаждении в сплаве
$\mathrm{Ni}_{47} \mathrm{Mn}_{42} \mathrm{In}_{11}$ наблюдается мартенситное превращение по типу $L 2_{1} \rightarrow 14 M$ с образованием модулированной структуры мартенсита [6]. Мартенсит 14M образуется также в двухкомпонентных сплавах с высокотемпературной памятью формы типа $\mathrm{Ni}-\mathrm{Al}$, и его кристаллографические особенности исследовали, например в [7]. Но этот мартенсит образуется из аустенита с другой кристаллической решеткой $-B 2$ или $L 1_{0}$, без участия магнитных эффектов.

В настоящей работе проведены исследования особенностей мартенситной структуры сплава Гейслера $\mathrm{Ni}_{47} \mathrm{Mn}_{42} \mathrm{In}_{11}$. Ее целью являлось изучение кристаллографии мартенситного превращения - определения типа мартенсита, габитусных плоскостей, ориентационных соотношений между высокотемпературной фазой и мартенситом, а также механизма мартенситного превращения, когда в процессе структурного превращения могут участвовать магнитные эффекты.

\section{2. Методика эксперимента}

Исследовали сплав $\mathrm{Ni}_{47} \mathrm{Mn}_{42} \mathrm{In}_{11}$, выплавленный методом электродуговой плавки в атмосфере аргона. После выплавки сплав был подвергнут гомогенизирующему отжигу при температуре $1123 \mathrm{~K}$ в течение $24 \mathrm{~h}$ с последующим охлаждением с печью.

Структурные исследования выполнены на оптическом микроскопе „Neophot-30“ на шлифах после травления. Электронно-микроскопические исследования выполняли на просвечивающем электронном микроскопе JEM-200СХ и сканирующем электронном микроскопе „Quanta-200“ с локальным микрорентгеноспектральным анализом в отделе электронной микроскопии ЦКП Испытательный центр нанотехнологий и перспективных материалов ИФМ УрО РАН. Электронно-микроскопические исследования проводили на фольгах, приготовленных по стандартной методике, в режимах 

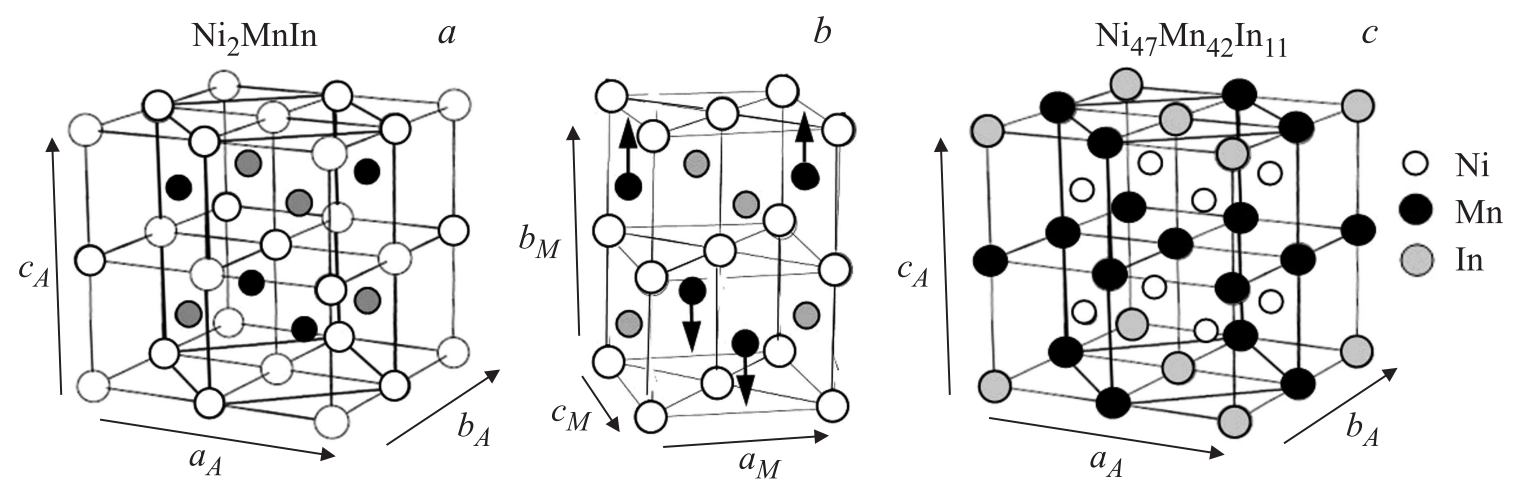

Pис. 1. Структура аустенита: $a-$ структура $L 2_{1}$ для сплава $\mathrm{Ni}_{2} \mathrm{MnIn}, b-$ вырезанная тетрагональная ячейка - прообраз мартенсита $14 M$, стрелки показывают направления спинов атомов $\mathrm{Mn}$ в антиферромагнитном состоянии; $c-$ предполагаемая упорядоченная структура $L 2_{1}^{\prime}$ для сплава $\mathrm{Ni}_{47} \mathrm{Mn}_{42} \mathrm{In}_{11}$, начало координат перенесено в атом In.

светло- и темнопольного анализов. Для идентификации фаз использовали метод микродифракции от выбранного участка. Дальнейший кристаллографический анализ мартенситной структуры проводили с использованием рассчитанных в программе „CaRine“ схем электронограмм и стереографических проекций, соответствующих конкретным ориентировкам кристаллов мартенсита и аустенита.

Рентгеноструктурные исследования выполнены на модернизированном дифрактометре ДРОН-1 с усовершенствованной приставкой ГП-2, позволяющей наклонять образец с точностью до 0.1 градуса и поворачивать его в плоскости образца с точностью 0.5 градуса. Приставка снабжена устройством для нагрева и охлаждения образца. Методика рентгеновских измерений подробно приведена в [6].

\section{3. Результаты исследования и обсуждение}

В высокотемпературной области исследуемый сплав $\mathrm{Ni}_{47} \mathrm{Mn}_{42} \operatorname{In}_{11}$ имеет кубическую кристаллическую решетку, упорядоченную по типу $L 2_{1}$ фазы [8]. При охлаждении в сплаве происходит мартенситное превращение, сопровождающееся перестройкой кристаллической решетки. Установлено [6], что образуется мартенсит $14 M$.

Имеющиеся в литературе данные по параметрам кристаллической решетки мартенсита $14 M$ различаются между собой в зависимости от состава сплава и концентрации, входящих в него, элементов. Главное различие, заключающееся в размере единичной ячейки кристаллической решетки, относится к наблюдениям сплавов разных групп: в трехкомпонентных сплавах Гейслера единичная ячейка $14 M$ содержит 56 атомов, а в двойных сплавах типа $\mathrm{Ni}-\mathrm{Al}$, с высокотемпературной памятью формы, - 28. В обоих случаях образуется 14-слойная структура типа $(5 \overline{2})$ по плотноупакованным плоскостям -\{111\} или $\{110\}$, в ГЦК- или ОЦК-решетках аустенита соответственно. В первом случае мартенсит образуется из аустенита со структурой $L 2_{1}$ (упорядоченная, кубическая из 16 атомов на основе 8 ячеек ОЦК), а во втором - из аустенита со структурой $L 1_{0}$ (упорядоченная из 8 атомов на основе ячейки ГЦК). Прообразом кристаллической решетки мартенсита $14 M$ в обоих случаях служит вырезанная из решетки аустенита тетрагональная ячейка: в первом случае состоящая из 8 атомов - с удвоенным параметром по оси $c$ относительно ОЦК-ячейки, а во втором - из 4 атомов, с одним параметром по оси $c$.

На рис. 1 представлены структура кристаллической решетки аустенита $L 2_{1}$ для сплава Гейслера, имеющего состав $\mathrm{Ni}_{2} \mathrm{MnIn}$ (рис. 1,a), и вырезанная тетрагональная ячейка - прообраз мартенсита $14 M$ (рис. 1,b). Предполагается, что в исследуемом сплаве $\mathrm{Ni}_{47} \mathrm{Mn}_{42} \mathrm{In}_{11}$, существенно отклоняющемся по составу от стехиометрического сплава Гейслера $\mathrm{Ni}_{2} \mathrm{MnIn}$, избыточные атомы $\mathrm{Mn}$ в структуре аустенита $L 2{ }_{1}$ замещают атомы Ni. Следует отметить, что с увеличением содержания марганца ферромагнитные свойства сплава значительно возрастают, поскольку атомы Mn имеют существенно бо́льший магнитный момент $-3.33 \mu_{\mathrm{B}}$, чем атомы $\mathrm{Ni}\left(0.36 \mu_{\mathrm{B}}\right)$. В тетрагональной ячейке (см. рис. $1, b)$ стрелками показаны направления спинов атомов марганца, соответствующие антиферромагнитному состоянию, которое может привести к дополнительному магнитному упорядочению кристаллической структуры. Возможно, в сплаве $\mathrm{Ni}_{47} \mathrm{Mn}_{42} \mathrm{In}_{11}$ имеет место также дополнительное упорядочение кристаллической структуры аустенита, связанное с замещением атомов индия атомами марганца. Например, с заменой половины смешанных In-Mn слоев атомов, перпендикулярных к оси $c$, на $\mathrm{Mn}$ слои, с формированием структуры $L 2_{1}^{\prime}$, - как показано на рис. $1, c$.

Параметры кристаллической решетки мартенсита $14 M$ в сплаве $\mathrm{Ni}_{47} \mathrm{Mn}_{42} \mathrm{In}_{11}$ были ранее определены нами [6] в процессе охлаждения с помощью измеренных рентгеновским методом периодов и углов решетки: сначала для высокотемпературной фазы аустенита со структурой $L 2_{1}$, затем - мартенсита при комнатной

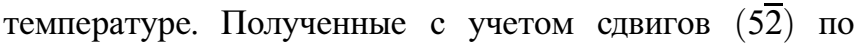




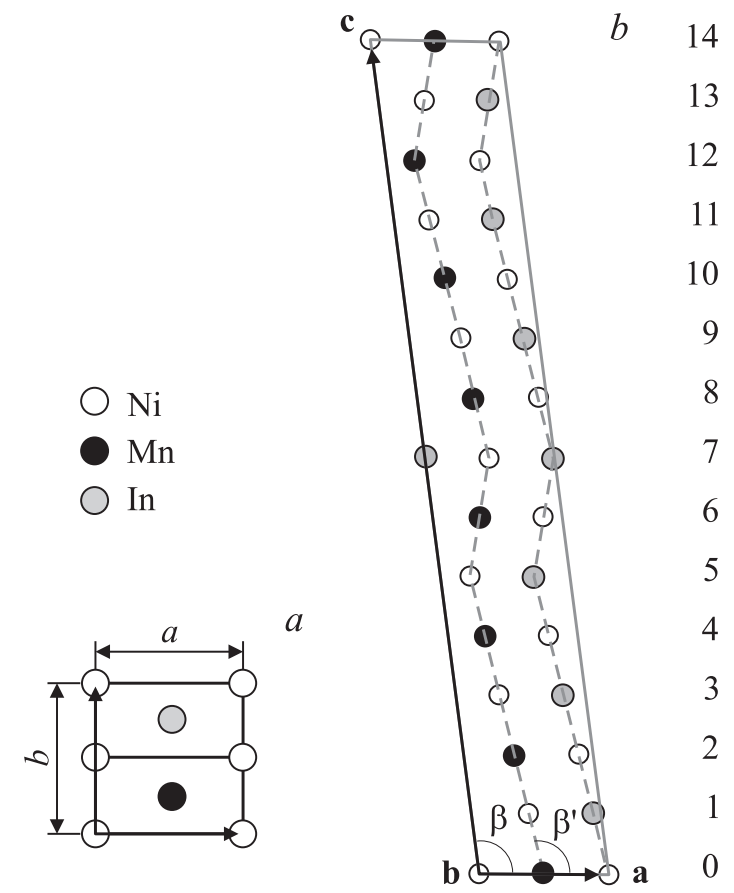

Рис. 2. Схема расположения атомов в единичной ячейке мартенсита $14 M$ сплава $\mathrm{Ni}_{47} \mathrm{Mn}_{42} \mathrm{In}_{11}$ после сдвигов по системе $(5 \overline{2})(110)[\overline{1} 10]: a, b-$ проекции на плоскости $(001)$ и $(0 \overline{1} 0)$ соответственно. Параметры ячейки мартенсита: $a=0.4244 \mathrm{~nm}$, $b=0.5993 \mathrm{~nm}, c=2.9687 \mathrm{~nm}, \beta=97.36^{\circ}\left(\beta^{\prime}=103.35^{\circ}\right)$.

системе (110)[110] параметры ячейки: $a=0.4244 \mathrm{~nm}$, $b=0.5993 \mathrm{~nm}, c=2.9687 \mathrm{~nm}, \alpha=90.57^{\circ}, \beta=97.36^{\circ}$, $\gamma=89.24^{\circ}$ характеризуют решетку мартенсита (рис. $2, a, b)$, как моноклинную длиннопериодную (если пренебречь незначительными отклонениями углов $\alpha$ и $\gamma$ от $90^{\circ}$ ). Базис единичной ячейки решетки мартенсита $14 M$ (из 56 атомов), внесенный в программу „CaRine“, позволил получать трехмерные изображения прямой и обратной решетки, их сечения, а также расчетные схемы электронограмм и стереографические проекции для различных ориентаций кристалла. Интересной возможностью также является расчет профиля рентгеновских пиков отражений Брэгга по углам $2 \theta$ (рис. 3) для мартенситного кристалла. Такой профиль наглядно характеризует особенности параметров кристаллической решетки мартенсита, который можно сравнивать с экспериментальными профилями подобных кристаллов в других сплавах.

При деформации решетки $L 2_{1}$ исходного аустенита посредством сдвигов $(5 \overline{2})$ плотноупакованных слоев атомов в системе (110)[110], можно ожидать конкретные ориентационные соотношения (ОC): (001) $)_{14 M} \|(110)_{L 2_{1}}$, $[100]_{14 M} \|[\overline{1} 10]_{L 2}$.

Эти соотношения представлены на рис. $4, a, b$ стереографическими проекциями мартенсита и аустенита $(001)_{14 M}$ (см. pис. $\left.4, a\right)$ и $(110)_{L 2_{1}}$ (см. рис. $\left.4, b\right)$ соответственно, которые можно использовать для прогнозирования возможных ориентаций кристаллов мартенсита, образующихся в кристалле аустенита с известной ориентацией. Заштрихованные области на проекциях показывают зоны кристаллографически неэквивалентных полюсов плоскостей или направлений. Для кубической решетки $L 2_{1}$ аустенита, имеющей высокую степень симметрии, заштрихованная область на стереографической проекции (см. рис. 4, $a$ ) занимает площадь одного стереографического треугольника, в вершинах которого располагаются полюсы $\{100\},\{110\}$ и $\{111\}$. Полная проекция содер-

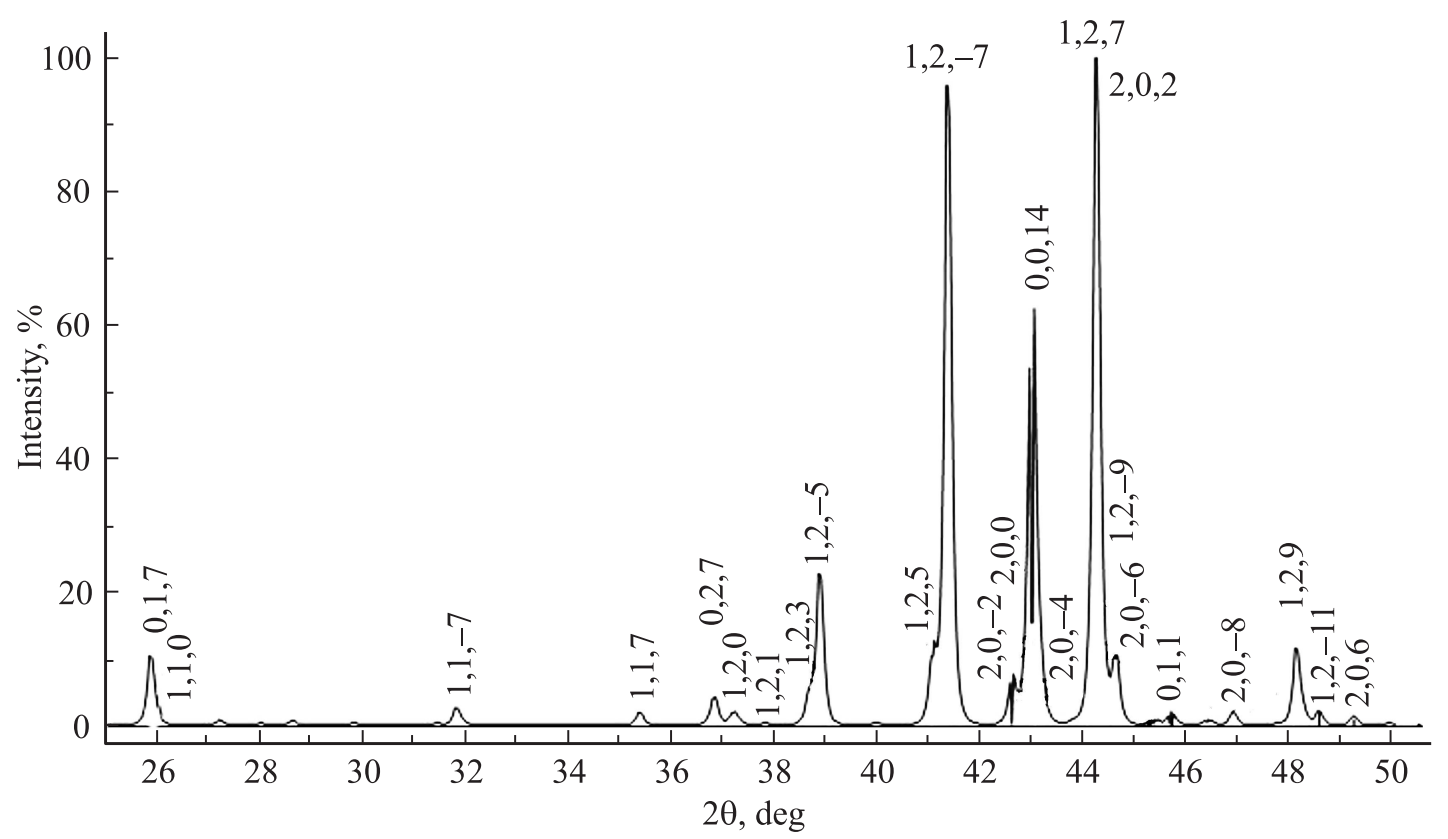

Рис. 3. Сплав $\mathrm{Ni}_{47} \mathrm{Mn}_{42} \mathrm{In}_{11}$. Рассчитанный профиль рентгеновских пиков отражений по углам $2 \vartheta\left(\lambda_{\mathrm{Cu}}=1.540562 \AA\right)$ для мартенсита $14 M$. 

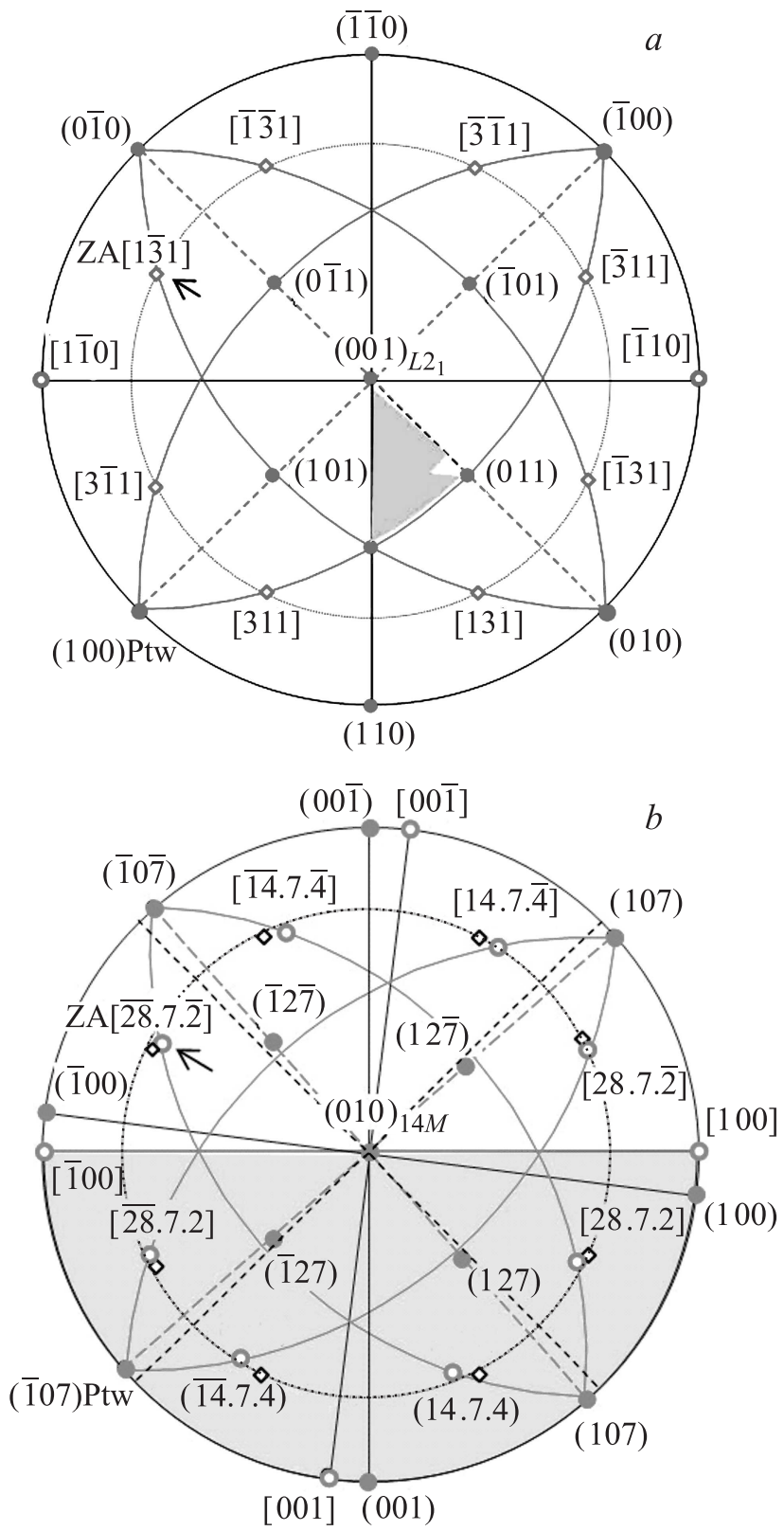

Pис. 4. Стереографические проекции (001) аустенита (a) и $(010)$ мартенсита $(b)$ при выполнении ориентационных соотношений $(\mathrm{OC}):(001)_{14 M}\left\|(110)_{L 2_{1}},[100]_{14 M}\right\|[\overline{1} 10]_{L 2_{1}}$. Жирным шрифтом выделены индексы полюсов плоскостей и направлений, входящих в ОС. Стрелками отмечены, выбранные при расшифровке, полюсы осей зон кристаллов $A$ и $M 1$ (рис. $5, a, b$ ). Обозначения: •, о - полюсы плоскостей и направлений соответственно; $\diamond-$ полюсы $\langle 131\rangle_{L 2_{1}}$, возможных О3 для кристалла $A$.

жит 24 таких треугольника, и это означает, что каждая ориентация плоскости или направления в аустените в общем случае имеет 24 эквивалентных варианта. Их может быть меньше, если соответствующий ориентации полюс лежит на границе или в вершине стереографического треугольника. В частности, плоскость сдвига в аустените $\{110\}$, имеет 6 вариантов, так как ее полюс лежит в общей вершине четырех стереографических треугольников, и таких вершин 6. Если учесть, что в каждом из 6 вариантов плоскости сдвига $\{110\}$ возможны два направления сдвига - например для $(110)-[\overline{1} 10]$ и $[1 \overline{1} 0]$, то для формирования мартенсита $14 M$, существует 12 кристаллографически эквивалентных вариантов ориентации его кристалла с исходным кристаллом аустенита при выполнении заданного типа ОС. В моноклинной решетке $14 M$, с пониженной симметрией, зона кристаллографически неэквивалентных полюсов, как можно видеть на рис. $4, b$, занимает половину площади стереографической проекции - два квадранта. Поэтому в мартенсите $14 M$ любая ориентация имеет два кристаллографически эквивалентных варианта, которые связаны между собой поворотом на $180^{\circ}$ вокруг оси $[010]_{14 M}$, и плоскость $(010)$ в данном случае не является плоскостью двойникования. Следует также отметить, что если для кубической решетки полюсы плоскостей и направлений с одноименными индексами совпадают между собой, то в моноклинной решетке $14 M$ мартенсита практически нет точно совпадающих полюсов плоскости и направления с одноименными индексами, за исключением полюсов (010) и [010]. Расхождение таких полюсов различно, но максимальное из них отвечает полюсам (001) и [001] — оно составляет 7.36.

Для кристаллографического анализа структур мартенсита $14 M$ важно учитывать возможные эквивалентные ориентации кристаллов мартенсита и определять в их числе двойниковые варианты, для чего необходимо знать плоскости двойникования в мартенсите $14 M$. Основные элементы двойникования мартенсита $14 M$, образующегося в двухкомпонентных сплавах с памятью формы типа $\mathrm{Ni}-\mathrm{Al}$ - с исходной структурой аустенита $B 2$ или $L 1_{0}$, - были рассчитаны по феноменологической теории в работе Мураками с соавторами [7] и экспериментально подтверждены рядом исследователей. Нам необходимо установить, насколько они применимы к мартенситу $14 M$ в трехкомпонентных сплавах Гейслера, в частности в сплаве $\mathrm{Ni}_{47} \mathrm{Mn}_{42} \mathrm{In}_{11}$, имеющих структуру кристаллической решетки исходного аустенита $L 2_{1}$.

На рис. 5, а представлена структура, состоящая из двух пластинчатых кристаллов мартенсита - $M 1$ и $M 2$, с клиновидным участком аустенита $(A)$ между ними. Внутри каждой пластины наблюдается полосчатый контраст, предположительно отвечающий следам плоскостей залегания дефектов упаковки мартенсита $14 M$ $(001)_{14 M} \|\{110\}_{L 2_{1}}$. С учетом направления полос внутренней структуры и следов межфазных границ пластины кристаллов $M 1$ и $M 2$ располагаются достаточно симметрично относительно проведенной нами штрихпунктирной линии. Оба направления на рис. 5, $а$ помечены стрелками-нормалями с цифрами 1 и 2 разного вида: утолщенной серой и тонкой черной. Видимая симметрия подсказывает, что пластинчатые кристаллы мартенсита находятся между собой в двойниковом соотношении, а штрихпунктирная линия может отвечать следу плоскости двойникования. 

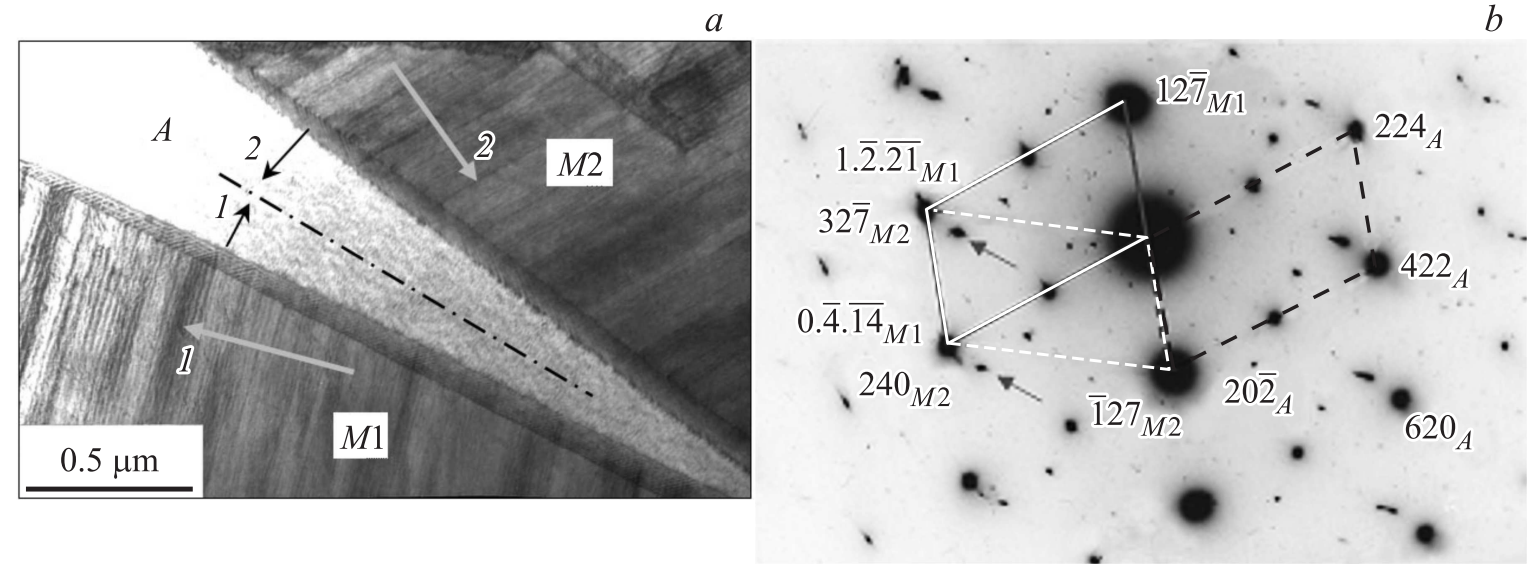

Zone axes: $[1 \overline{3} \overline{1}]_{A}+[\overline{28} .7 . \overline{2}]_{M 1}+[14 . \overline{7} \cdot 4]_{M 2}$
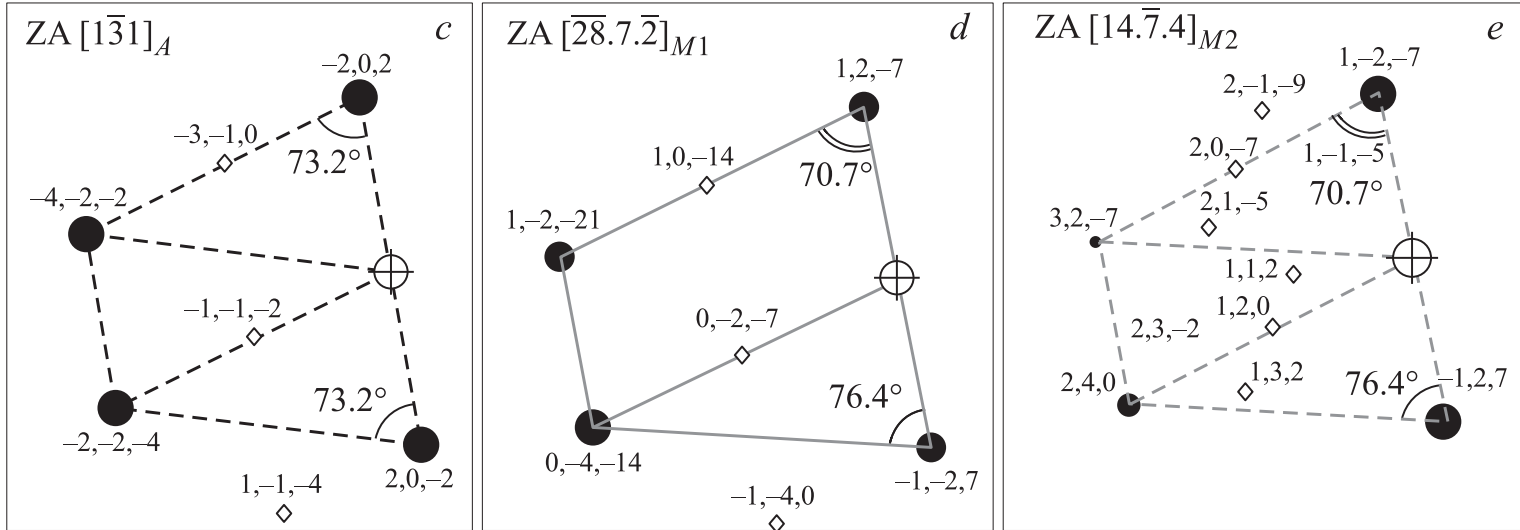

Рис. 5. Мартенситная структура сплава $\mathrm{Ni}_{47} \mathrm{Mn}_{42} \operatorname{In}_{11}: a-$ пластины мартенсита $M 1$ и $M 2$ с участком аустенита $A$ между ними; $b$ - микродифракция с расшифровкой рефлексов аустенита и мартенсита (стрелками отмечены неустановленные рефлексы); $c, d, e-$ рассчитанные в „CaRine“ схемы электронограмм для кристаллов аустенита и мартенсита. Обозначения: •, •- рефлексы мартенсита разной интенсивности; $\diamond-$ сверхструктурные рефлексы чрезвычайно малой интенсивности.

На микродифракции (рис. 5, $b$ ) выделяется сетка из наиболее ярких рефлексов. Она хорошо соответствует одному из возможных вариантов оси зоны (О3) $\langle 113\rangle$ аустенита с решеткой $L 2_{1}$ (см. рис. $\left.1, a\right)$. Выберем, например, ориентацию аустенита с О3 [1힐. Но есть отличие: на микродифракции (см. рис. $5, b)$ в сетке ярких рефлексов достаточно четко наблюдаются менее интенсивные сверхструктурные рефлексы, которых не должно быть в обратной решетке структуры $L 2_{1}$. Такие рефлексы могут принадлежать обратной решетке аустенита с уточненной структурой $L 2_{1}^{\prime}$ для сплава $\mathrm{Ni}_{47} \mathrm{Mn}_{42} \mathrm{In}_{11}$ (рис. 1,c). Однако, их расчетная интенсивность по программе „CaRine“ (см. рис. 5,c) чрезвычайно мала, и они вряд ли могут наблюдаться на электронограмме. Возможно присутствие четких сверхструктурных рефлексов на электронограмме обязано существенному магнитному взаимодействию между атомами $\mathrm{Mn}$ в антиферромагнитном состоянии (см. рис. $1, b$ ), что не учитывается в программе „CaRine“.

Наблюдаемое на электронограмме (см. рис. 5, b) расположение сверхструктурных рефлексов для аустенита со структурой $L 2_{1}^{\prime}$ может отвечать только 8 ориентациям с О3 $\langle 113\rangle$ (из общего числа 12), включая выбран- ную нами ориентацию - O3 [1ํㅣㄹ. На стереографической проекции аустенита (см. рис. 4, $a$ ) они отмечены символом $\diamond$. Анализ показал, что этим ориентациям аустенита, перенесенным на проекцию мартенсита (см. рис. $4, b)$, достаточно близки 8 ориентировок мартенсита, с различной степенью близости к полюсам $\diamond$ для двух групп по 4 ориентировки - с O3 $\langle 28.7 .2\rangle_{14 M}$ и c O3 $\langle 14.7 .4\rangle_{14 M}$. Проведенный в „CaRine“ расчет схем электронограмм показал, что обе группы ориентаций O3 характеризуются также достаточно близкими сетками рефлексов по отношению к сетке рефлексов аустенита c O3 $[1 \overline{3} 1]_{L 2_{1}^{\prime}}$. Таким образом, ориентировка кристалла мартенсита $[\overline{28} \cdot 7 . \overline{2}]_{14 M}$, близкая к ориентировке аустенита $\mathrm{O} 3[1 \overline{3} 1]$ (см. рис. 4, $a, b$ ), вполне может присутствовать на электронограмме (см. рис. $5, b)$ со своими рефлексами, практически совпадающими с аустенитными, из-за чего ее трудно обнаружить. Достаточно яркие рефлексы на электронограмме (см. рис. $5, b)$ не позволяют увидеть возможное незначительное расщепление их на аустенитные и мартенситные. Мы можем считать, что ориентировки $[1 \overline{3} 1]_{L 2_{1}^{\prime}}$ и $[\overline{28} .7 . \overline{2}]_{14 M}$, принадлежат интересующим нас кристаллам аустенита и мартенсита - $A$ и $M 1$ (что подтвердил последующий анализ). 

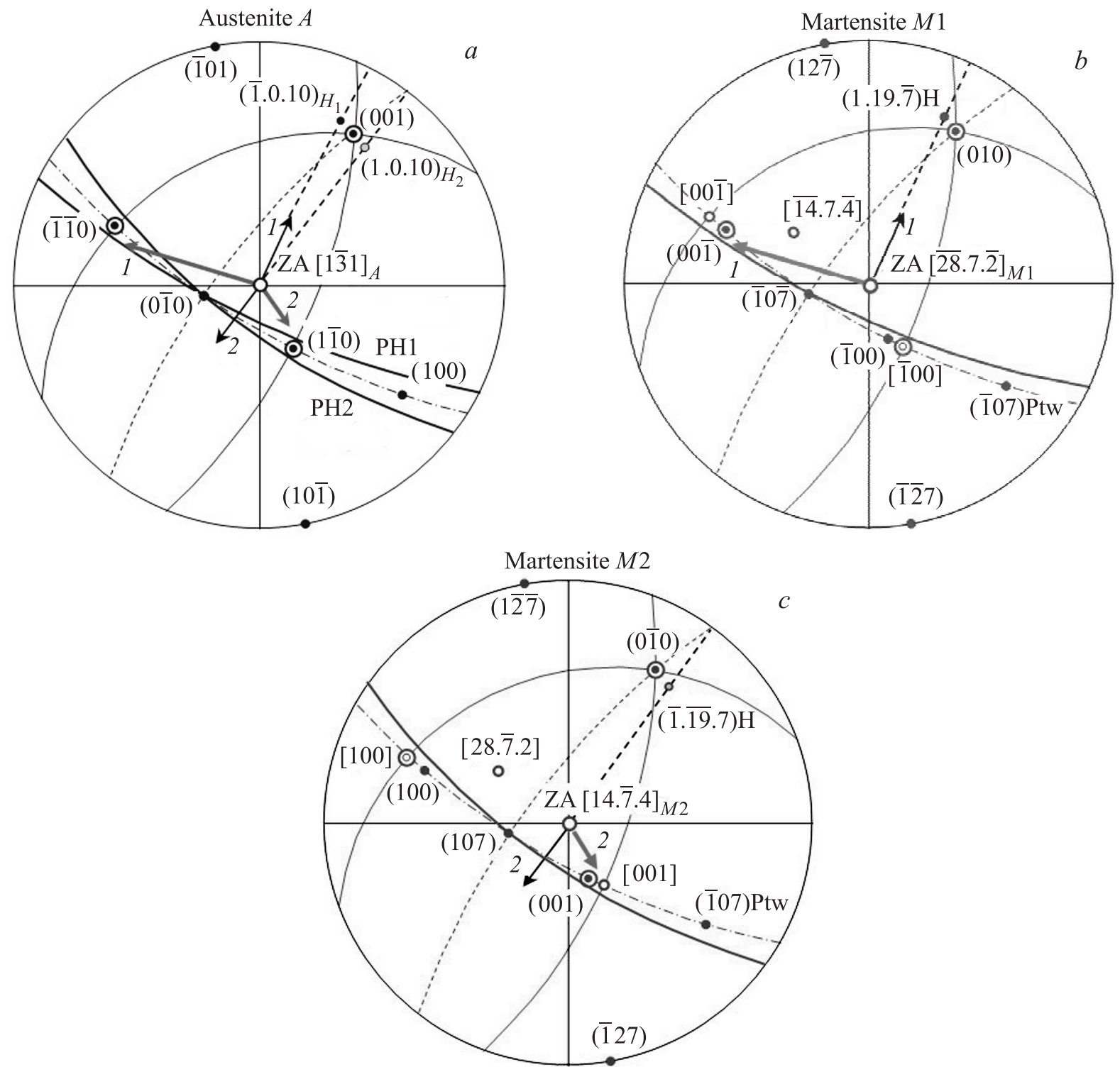

Рис. 6. Стереографические проекции для кристаллов аустенита - $A(a)$ и мартенсита - M1 (b), M2 (c). Жирным шрифтом выделены индексы плоскостей и направлений, входящих в ОС, а также - плоскостей габитусов и двойникования $M 1 / M 2$. Жирными линиями выделены следы габитусов, а пунктирной линией - след плоскости двойникования. Стрелки-нормали 1,2 к габитусам и полосчатому контрасту пластин параллельно перенесены с рис. 5, $a$. Обозначения: •, о — полюсы плоскостей и направлений соответственно; - , (?) совпадающие полюсы плоскостей и направлений соответственно, входящие в ОС.

Соответствующие им расчетные схемы электронограмм приведены на рис. 5, $c, d$. На них символами $\diamond$ отмечены сверхструктурные рефлексы чрезвычайно малой интенсивности, которые хорошо соответствуют сверхструктурным рефлексам, четко наблюдающимся на микродифракции (см. рис. $5, b)$. Видно также, что сверхструктурные рефлексы аустенита практически накладываются на аналогичные рефлексы мартенсита, и в этих случаях также трудно наблюдать возможное расщепление рефлексов двух фаз.

Для более подробного анализа и подтверждения определенных ориентаций кристаллов аустенита $(A)$ и мартенсита $(M 1)$ необходимо рассмотреть соответствующие им стереографические проекции с осями зон в центрах. Эти проекции, построенные с помощью программы „CaRine“, приведены на рис. $6, a, b$ с сохранением ориентаций следов плоскостей в структуре (см. рис. $5, a)$ и расположения рефлексов главного ряда на электронограмме (см. рис. $5, b$ ).

Как и следовало ожидать, почти совпадающее расположение полюсов на стереографических проекциях аустенита и мартенсита (см. рис. $6, a, b$ ) подтверждает соответствие наблюдаемых ориентационных соотношений между двумя кристаллами заданным на рис. $4, a, b$ мартенситным OC: $(001)_{14 M} \|(110)_{L 2_{1}^{\prime}}$, $[100]_{14 M} \|[\overline{1} 10]_{L 2_{1}^{\prime}}$. Важно отметить, что след от плос- 
костей $(010)_{14 M} \|(001)_{L 21}$, также входящих в OC, соответствует направлению штрихпунктирной линии, нанесенной на изображении мартенситной структуры (см. рис. $5, a)$. Анализ проекций на рис. $6, a, b$ показывает, что ориентировка мартенсита с О3 $[\overline{28} .7 . \overline{2}]_{14 M}$ отвечает кристаллу $M 1$ (а не $M 2$ ): утолщенная светлая стрелка „1“, соответствующая в структуре (см. рис. $5, a$ ) нормали к полосчатому контрасту в пластине $M 1,-$ с достаточной близостью на проекции (см. рис. $6, b)$ указывает на полюс плоскости залегания дефектов упаковки - $(001)_{14 M}$.

Чтобы определить ориентировку мартенситного кристалла $M 2$, присутствующего в структуре (см. рис. $5, a$ ), использовали ограничивающее условие для кристалла $M 2$. Оно состоит в том, что утолщенная стрелка „2“, перенесенная со структуры (см. рис. 5, $a$ ) на его стереографическую проекцию (рис. $6, c)$, должна указывать, как и в случае кристалла $M 1$, - на полюс $(001)_{14 M}$. Анализ показал, что для обеспечения такого условия кристалл $M 2$ должен быть связан с кристаллом $M 1$ двойниковым соотношением, по одной из двух плоскостей $(\overline{1} 07)_{14 M}$ или $(107)_{14 M}$ (что соответствует повороту на $180^{\circ}$ вокруг нормали к выбранной плоскости), или поворотом на $90^{\circ}$ вокруг направления $[010]_{14 M}$. В каждом из трех случаев мы получаем кристаллографически эквивалентный вариант мартенситного кристалла. Чтобы правильно выбрать один из трех вариантов мы воспользовались вторым ограничивающим условием. Оно связано с ориентацией плоскости габитуса. Структура на рис. 5, $a$ позволяет нам определить для каждого из двух мартенситных кристаллов направление следа плоскости габитуса (или связанное с ним направление проекции нормали к плоскости габитуса на плоскость фольги). Зная ориентационное соотношение между двумя мартенситными кристаллами, мы можем определить оба направления следов габитусов в одних координатах и рассчитать по ним нормаль к плоскости габитуса, которая должна быть одинакова в двух кристаллах (без учета знаков индексов). Решение такой кристаллографической задачи позволило определить единственно возможный из указанных выше трех предполагаемых вариантов ориентации кристалла $M 2$ - двойниковый по плоскости $(\overline{1} 07)_{14 M} \|(010)_{L 2}$ с с О3 [14.7.7.4]. Одновременно удалось рассчитать индексы плоскостей габитуса двух мартенситных кристаллов, которые одинаковы по типу: $(\overline{1} \cdot 0.10)_{\mathrm{H} 1}$ и $(\overline{1} \cdot 0 . \overline{1} 0)_{\mathrm{H} 2}$.

На рис. 5,e приведена расчетная схема электронограммы для мартенсита $M 2$. Как видно, она характеризуется расположением своих рефлексов весьма близким к рефлексам аустенита $A$ (см. рис. 5, $c$ ) и почти совпадающим с рефлексами мартенсита $M 1$ (рис. $5, d$ ). Соответствующая стереографическая проекция представлена на рис. $6, c$. Видно, что утолщенная стрелка „2“ указывает на полюс $(001)_{14 M} \|\{110\}_{L 2_{1}^{\prime}}$, отвечающий плоскости внутреннего двойникования (или залегания дефектов упаковки) в пластине $M 2$. На всех стереографических проекциях (см. рис. $6, a, b, c)$ жирными линиями показаны следы рассчитанных габитусных плоскостей. Таким образом, в структуре на рис. 5, $a$ мы наблюдаем мартенситные пластины, находящиеся в двойниковом соотношении по плоскости $(\overline{1} 07)_{14 M}$. Следует отметить, что плоскость $(010)_{14 M}$, след которой совпадает с нанесенной на структуре (рис. $5, a$ ) штрихпунктирной линией, не является плоскостью двойникования. Эта плоскость оказалась перпендикулярной найденной плоскости двойникования (107) 14 , она, вероятно, является „плоскостью сдвига“ согласно приведенной в [9] классической схеме элементов двойникования.

Следует отметить, что не все рефлексы, присутствующие на микродифракции (см. рис. $5, b$ ), идентифицированы по принадлежности к кристаллам $A$ и $M 1$ и $M 2$. Большинство их - из числа рефлексов с пониженной интенсивностью, присутствуют в сетках, но не видны изза слишком низкой расчетной интенсивности. Но есть также рефлексы - указанные малыми стрелками (см. рис. $5, b$ ), которые не удалось связать с какой-либо конкретной сеткой из двух фаз. Эти рефлексы могут соответствовать соседней ориентировке мартенсита $14 M$, не вошедшей в рассмотрение.

Найденное двойниковое соотношение между мартенситными кристаллами по плоскости $\{107\}$ мартенсита $14 M$ не означает возможность такого двойникования в исследованном сплаве $\mathrm{Ni}_{47} \mathrm{Mn}_{42} \mathrm{In}_{11}$, и мы не встречали в литературе данные об экспериментальном наблюдении $\{107\}$-двойникования в сплавах Гейслера. Однако известно, что эта плоскость была получена [7] расчетом по феноменологической теории при исследовании мартенситного превращения $L 1_{0} \rightarrow 14 M$ в сплавах с памятью формы типа $\mathrm{Ni}-\mathrm{Al}$, - как возможная при смешанном типе двойникования в сочленениях мартенситных кристаллов по модели „алмаза“ при самоаккомодации. Такой факт указывает на некоторую общность кристаллографических особенностей двух групп сплавов при мартенситном превращении, и она, безусловно, должна быть. Главное различие двух групп сплавов, обладающих памятью формы при образовании мартенсита $14 M$, связано с параметром аустенита с (в мартенсите параметр b). Если этот параметр не связан геометрически с системой сдвига (110)[110], действующей в мартенситном превращении, то кристаллогеометрические особенности мартенсита $14 M$ в различных сплавах должны быть схожи между собой. Так, например, в сплавах со структурой Гейслера параметр с удвоен относительно базовой ОЦК-ячейки, а в двухкомпонентных сплавах одинарный. Это различие в записи плоскостей аустенита отражается в 3-ем индексе, а мартенсита - во 2-м. Что касается плоскости двойникования $(107)_{14 M}$, то ее второй индекс равен нулю. Поэтому плоскость двойникования $(107)_{14 M}$ может быть применима не только к двухкомпонентным сплавам типа $\mathrm{Ni}-\mathrm{Al}$, но также к трехкомпонентным сплавам Гейслера.

Тем не менее, между двумя группами сплавов с памятью формы есть более глубокое различие: в трехкомпонентных сплавах Гейслера в процессе мартенситного превращения дополнительно участвуют магнитные эффекты. Их влияние на процесс образования мартенсита $14 M$ может вносить свои кристаллографические 
особенности, которые могут быть выявлены при дальнейшем исследовании.

\section{4. Заключение}

Исследована структура сплава $\mathrm{Ni}_{47} \mathrm{Mn}_{42} \mathrm{In}_{11}$ после отжига методами оптической металлографии, электронной микроскопии, а также рентгеноструктурным методом. Показано, что при охлаждении в сплаве $\mathrm{Ni}_{47} \mathrm{Mn}_{42} \mathrm{In}_{11}$ наблюдается мартенситное превращение по типу $L 2_{1} \rightarrow 14 M$ с образованием модулированной структуры мартенсита. Температура мартенситного перехода близка к температуре Кюри аустенита.

Проведен кристаллографический анализ структуры мартенсита с использованием расчетных схем электронограмм и стереографических проекций по уточненному базису ячейки кристаллической решетки с учетом экспериментально определенных параметров и максимального приближения к стехиометрическому составу сплава.

Экспериментально определены ориентационные соотношения между высокотемпературной $L 2_{1}$ фазой и мартенситом 14M: $(001)_{14 M}\left\|(110)_{L 2_{1}},[100]_{14 M}\right\|[\overline{1} 10]_{L 2_{1}}$, и, отвечающие им, габитусные плоскости мартенситных пластин $(\overline{1} .0 .10)_{L 2_{1}}$ и $(1.0 .10)_{L 2_{1}}$.

Показано, что наблюдаемый внутри мартенситных пластин полосчатый контраст отвечает плоскостям залегания дефектов упаковки: (001) ${ }_{14 M} \|\{110\}_{L 21}$.

Между соседними пластинами мартенсита $14 M$ обнаружено двойниковое соотношение по плоскости $(\overline{1} 07)_{14 M}$, которая, как известно из литературы, была рассчитана с использованием феноменологической теории применительно к двухкомпонентным сплавам с памятью формы типа $\mathrm{Ni}-\mathrm{Al}$, и рассматривалась авторами как возможная плоскость двоникования смешанного типа в структуре мартенсита $14 M$.

\section{Список литературы}

[1] Y. Sutou, Y. Imano, N. Koeda, T. Omori, R. Kainuma, K. Ishida, K. Oikawa. Appl. Phys. Lett. 85, 4358 (2004).

[2] W. Ito, Y. Imano, R. Kainuma, Y. Sutou, K. Oikawa, K. Ishida. Metall. Mater. Trans. A 38 ${ }^{\mathbf{a}}, 759$ (2007).

[3] Ю.В. Калетина, Е.Г. Герасимов. ФТТ 56, 1583 (2014).

[4] Ю.В. Калетина, Е.Г. Герасимов, В.М. Счастливцев, Е.А. Фокина, П.Б. Терентьев. ФММ 114, 911 (2013).

[5] V.D. Buchelnikov, V.V. Sokolovskiy. Phys. Met. Metallogr. 112, 633 (2011).

[6] Ю.В. Калетина, Н.Ю. Фролова, В.М. Гундырев, А.Ю. Калетин. ФТТ 58, 1606 (2016).

[7] Y. Murakami, K. Otsuka, S. Hanada, S. Watanabe. Mater. Sci. Eng. A 189, 191 (1994).

[8] Х. Варлимонт, Л. Дилей. Мартенситные превращения в сплавах на основе меди, серебра и золота / Пер. с англ. Наука, М. (1980), 208 с.

[9] М.В. Классен-Неклюдова. Механическое двойникование кристаллов. Изд-во АН СССР, М.(1960), 261 с. 